\title{
Photoprotection and optimization of sucrose usage contribute to faster recovery of photosynthesis after water deficit at high temperatures in wheat
}

Pedro M. P. Correia ${ }^{1 *}$, Anabela Bernardes da Silva ${ }^{1}$, Thomas Roitsch ${ }^{2,3}$, Elizabete Carmo-Silva ${ }^{4}$, Jorge Marques da Silva ${ }^{1}$

${ }^{1}$ BioISI - Biosystems \& Integrative Sciences Institute, Faculdade de Ciências da Universidade de Lisboa, Campo Grande, 1749-016 Lisboa, Portugal

${ }^{2}$ Department of Plant and Environmental Sciences, Section of Crop Science, Copenhagen University, Højbakkegård Allé 13, 2630 Tåstrup, Denmark

${ }^{3}$ Department of Adaptive Biotechnologies, Global Change Research Institute, CAS, 60300 Brno, Czech Republic

${ }^{4}$ Lancaster Environment Centre, Lancaster University, Library Avenue, Lancaster, LA1 4YQ, UK

\section{Correspondence}

*Corresponding author, e-mail: pmpcorreia@fc.ul.pt

\begin{abstract}
Plants are increasingly exposed to events of elevated temperature and water deficit, which threaten crop productivity. Understanding the ability to rapidly recover from abiotic stress, restoring carbon assimilation and biomass production, is important to unravel crop climate resilience. This study compared the photosynthetic performance of two Triticum aestivum L. cultivars, Sokoll and Paragon, adapted to the climate of Mexico and UK, respectively, exposed to one week water deficit and high temperatures, in isolation or combination. Measurements included photosynthetic assimilation rate, stomatal conductance, in vitro activities of Rubisco (EC 4.1.1.39) and invertase (INV, EC 3.2.1.26), antioxidant capacity and chlorophyll $a$ fluorescence. In both genotypes, under elevated temperatures and water deficit $\left(\mathrm{WD} 38^{\circ} \mathrm{C}\right)$, the photosynthetic limitations were mainly due to stomatal restrictions and to a decrease in the electron transport rate. Chlorophyll $a$ fluorescence parameters clearly indicate differences between the two genotypes in the photoprotection when subjected to WD $38^{\circ} \mathrm{C}$ and showed faster recovery of Paragon after stress relief. The activity of the cytosolic invertase (CytINV) under these stress conditions was strongly related to the fast photosynthesis recovery of Paragon. Taken together, the results suggest that optimal sucrose export/utilization and increased photoprotection of the electron transport machinery are important components to limit yield fluctuations due to water shortage and elevated temperatures.
\end{abstract}


Abbreviations - A, net photosynthesis assimilation rate; cytINV, cytosolic invertase; ETR, electron transport rate; FRAP, ferric reducing antioxidant power; gs, stomatal conductance; LHCII, Lightharvesting complex II, LRWC, leaf relative water content; LWP, leaf water potential; NPQ, total nonphotochemical quenching; PAR, Paragon; Qa, quinone A; Qb, quinone B; qN, non-photochemical quenching; qP, photochemical quenching; RCA, Rubisco activase; RH, relative humidity; RuBPribulose 1,5-biphosphate; SOK, Sokoll; SDW, soil dry weight; SFC, soil field capacity; SRWC, soil relative water content; TEAC, Trolox equivalents antioxidant capacity; TSP, Total soluble protein; vacINV, vacuolar invertase; Vi- Rubisco initial activity; Vt- Rubisco total activity; WD, water deficit; $\mathrm{WD} 25^{\circ} \mathrm{C}$, water deficit at $25^{\circ} \mathrm{C}$; WD $38^{\circ} \mathrm{C}$, water deficit at $38^{\circ} \mathrm{C}$; WW, well-watered; WW $25^{\circ} \mathrm{C}$, wellwatered at $25^{\circ} \mathrm{C}$; WW $38^{\circ} \mathrm{C}$, well-watered at $38^{\circ} \mathrm{C}$.

\section{Introduction}

Global warming is a serious threat to crop production. Wheat is the world's most harvested crop per area, however, wheat yield is below the average of the other major crops (e.g. maize and rice) being therefore only the second most-produced cereal grain, with $26 \%$ of the world share (FAOSTAT 2017). Around $40 \%$ of the global wheat yield fluctuations are explained by climatic variation, and heatwaves and drought are among the principal stressors (Deryng et al. 2014, Zampieri et al. 2017). Each degree-Celsius increase in global mean temperature reduces, on average, the global yield of wheat by $6 \%$ (Zhao et al. 2017). To improve wheat yield in a changing climate, and ensure food security for an increasing world population, it is essential to comprehend how wheat plants respond to fluctuations in temperature and water availability, and the mechanisms involved in fast recovery of plant growth upon relief from high temperatures and extended drought.

When subjected to high temperatures, plants usually use evaporative cooling to reduce leaf temperature (Carmo-Silva et al. 2012, Costa et al. 2013). However, in response to water shortage, higher plants close the stomata to limit water loss by transpiration. When both conditions are present, stomatal closure reduces transpiration and consequently the plant temperature rises and intercellular $\mathrm{CO}_{2}$ concentration decreases (Chaves et al. 2003, Carmo-Silva et al. 2012, Duque et al. 2013) . High temperatures and drought negatively affect photosynthetic $\mathrm{CO}_{2}$ fixation at different levels, depending on the stress intensity, decreasing biomass accumulation (Zandalinas et al. 2018, Lamaoui et al. 2018, Tricker et al. 2018, Raja et al. 2020). Even if high temperature increases the maximum rate (Vmax) of the primary carboxylation enzyme of $\mathrm{C}_{3}$ photosynthesis (Rubisco, EC 4.1.1.39), it also increases the inhibition of Rubisco by sugar phosphate derivatives and thus Rubisco activation state decreases (Salvucci and Crafts-Brandner, 2004a,b). The efficiency of Rubisco depends on the activity of Rubisco's catalytic chaperone, Rubisco Activase (RCA), to promote the release of inhibitory sugar phosphates from active sites. However, RCA is extremely thermal sensitive and depends on the redox status and ADP/ATP ratio (Carmo-Silva et al. 2015). To improve plant tolerance to increased 
temperatures, bioengineering approaches aiming to enhance Rubisco activity by increasing the thermotolerance of RCA have been suggested (Scafaro et al. 2016, Mueller-Cajar 2017, Shivhare and Mueller-Cajar 2017, Scafaro et al. 2019, Degen et al. 2020). Lower internal $\mathrm{CO}_{2}$ concentration and high temperatures also reduce Rubisco specificity for $\mathrm{CO}_{2}$ relative to $\mathrm{O}_{2}$, resulting in an increase of photorespiration, which leads to the release of previous fixed $\mathrm{CO}_{2}$ and higher demand for ATP (Walker et al. 2016).

Moreover, imbalances between $\mathrm{CO}_{2}$ assimilation and the rate of light capture usually lead to an excess of energy in the system that can result in reactive oxygen species (ROS) formation and photoinhibition if the capacities of dissipation, scavenging and repairing are exceeded (Yamamoto 2016). Among the main energy dissipation mechanisms are the non-photochemical quenching (qN, generally compartmented in three major components, energy-dependent quenching, qE, state-transition quenching, qT, and photoinhibition quenching, qI), cyclic electron flow around photosystem I and chlororespiration (Rumeau et al. 2007, Ruban 2016, Wang and Fu 2016). ROS detoxification is generally conducted enzymatically and by the production of several antioxidant compounds (Mittler et al. 2004; Foyer 2018; Begum et al. 2019) When energy dissipation and ROS detoxification fails, oxidative damage occurs. Many studies reported the reduction of the electron transfer from water to $\mathrm{NADP}^{+}$, due to reversible and irreversible inhibition of photosystem II (PSII) caused by oxidative stress in face of elevated temperatures and/or drought. The main processes involved are the damage of the oxygen-evolving complex (Heckathorn et al. 1998, Tiwari et al. 2008, Chen et al. 2016), the degradation and aggregation of the D1 protein (Kamata et al. 2005, Komayama et al. 2007, Allakhverdiev et al. 2008, Takahashi and Murata 2008) and changes on the membrane fluidity (Gounaris et al. 1983, Aronsson et al. 2008, Yamamoto 2016a).

Therefore, when photosynthetic performance and plant growth are challenged by water shortage and elevated temperatures, optimization of sucrose export, uptake, and utilization, e.g. through adjustment of source - sink relations via invertase activity (INV, EC 3.2.1.26), can contribute to reducing yield fluctuations. Invertases mediate the hydrolytic cleavage of sucrose into hexose monomers and are involved in regulating carbohydrate partitioning, developmental processes, hormone responses and biotic and abiotic interactions (Roitsch and González 2004). Invertases localized in the vacuole (VacINVs) play a major role in the osmotic regulation (Nägele et al. 2010, Ruan 2014, Weiszmann et al. 2018), while cytosolic invertases (CytINVs) control sugar homeostasis and the maintenance of constant glucose levels to sustain cellular functions (Ruan et al. 2010, Lunn 2016, Figueroa and Lunn 2016).

The aims of the present study were to (1) characterise the photosynthetic limitations of two wheat genotypes, Paragon and Sokoll, adapted to distinct climate conditions, under water deficit and/or high temperature, and (2) to determine which factors are responsible for photosynthetic performance and recovery from high temperature in the absence or presence of water deficit. To test the hypothesis that the UK-adapted cultivar Paragon would be less resistant to heat stress and water deficit compared 
to the Mexican-adapted cultivar Sokoll, the two genotypes were subject to water deficit and elevated temperatures, in isolation or in combination, and compared for net assimilation rate, stomatal conductance, Rubisco and invertase in vitro activities, antioxidant capacity and chlorophyll $a$ fluorescence.

\section{Materials and methods}

\section{Plant growth conditions}

Two Triticum aestivum L. (wheat) genotypes were selected on the basis that these are adapted to distinct climate conditions: Paragon is a traditional UK spring wheat elite cultivar, while Sokoll is a syntheticderived cultivar developed by the International Maize and Wheat Improvement Centre (CMMYT, Mexico). Plants of both genotypes were grown from seeds in a controlled environment chamber (Fitoclima $5000 \mathrm{EH}$, Aralab) in 1-L pots containing horticultural substrate (Compo Sana Universal, Compo Sana). Light was provided by fluorescent lamps (Osram Lumilux L 58W/840 cool white lamps) placed at specific distances from the plants to obtain an average photosynthetic photon flux density (PPFD) of $300 \mu \mathrm{mol} \mathrm{m} \mathrm{m}^{-2} \mathrm{~s}^{-1}$ at the top of the canopy, with a photoperiod of $16 \mathrm{~h}$. Due to space constraints, temperature assays were performed in two consecutive experiments. After full germination, all plants were initially grown under a control temperature $\left(25 / 18^{\circ} \mathrm{C}\right.$ day/night), with $50 \%$ relative humidity $(\mathrm{RH})$ for 21 days.

For experiments under control temperature, plants remained at $25 / 18^{\circ} \mathrm{C}$ (day/night) with $50 \%$ RH throughout the experiment. Three weeks post-germination plants were randomly assigned to two irrigation treatments: five plants per cultivar were maintained well-watered (WW; minimum $80 \%$ field capacity, WW $25^{\circ} \mathrm{C}$ ) throughout the experiment and five plants were subject to water deficit (WD, $30 \pm 5 \%$ field capacity, $\mathrm{WD} 25^{\circ} \mathrm{C}$ ) for 7 days. For experiments under elevated temperature, 21-day-old plants were also exposed to high temperatures $\left(38 / 31^{\circ} \mathrm{C}\right.$ day/night) with $60 \% \mathrm{RH}$ and randomly assigned to the irrigation treatments: ten plants per cultivar were maintained WW $(80 \pm 5 \%$ field capacity, $\left.\mathrm{WW} 38^{\circ} \mathrm{C}\right)$ and ten plants were subject to WD $\left(30 \pm 5 \%\right.$ field capacity, WD $\left.38^{\circ} \mathrm{C}\right)$ for 5 days. From the 10 plants allocated to $\mathrm{WW} 38^{\circ} \mathrm{C}$ or $\mathrm{WD} 38^{\circ} \mathrm{C}, 5$ were randomly selected for recovery after 5 days of stress, re-watered and maintained at control temperatures for 7 days. WD was established by withholding watering and sustaining a minimum of $30 \pm 5 \%$ field capacity. The soil water content was determined gravimetrically by weighing the pots, and irrigation was provided to compensate evapotranspiration and keep the field capacity in the WW and WD pots. Leaf samples for biochemical analyses were collected at the end of the respective temperature and irrigation treatment, 5-7 $\mathrm{h}$ after the beginning of the photoperiod, frozen into liquid nitrogen and stored at $-80^{\circ} \mathrm{C}$.

\section{Leaf and soil water status}

Plant water status was estimated by leaf relative water content (LRWC) following the methodology described by Čatský (1960). Fresh leaf samples from the flag leaf $\left(1-2 \mathrm{~cm}^{2}\right)$ were collected, fresh weight 
was immediately measured in an electronic scale (Sartorius BP221S), turgid weight (LTW) was determined after saturating samples by immersion in deionized water overnight, and dry weight (LDW) was measured after oven-drying samples at $70^{\circ} \mathrm{C}$ for $48 \mathrm{~h}$. Soil relative water content (SRWC) was determined by following a similar procedure; although soil field capacity (SFC) was achieved by watering the pots to saturation and allowing water drainage for 2 hours, and dry weight (SDW) was measured after oven-drying samples at $110^{\circ} \mathrm{C}$ for $36 \mathrm{~h}$. Leaf water potential was measured with a C-52 thermocouple chamber (Wescor), $20 \mathrm{~mm}^{2}$ leaf discs were cut and equilibrated for $30 \mathrm{~min}$ in the chamber before the readings were recorded by a PSYPRO water potential datalogger (Wescor) in the psychrometric mode.

\section{Thermal imaging}

Thermal images were obtained using a thermal camera (Flir 50bx, FLIR Systems Inc.) with emissivity set at 0.95 and approximately $1 \mathrm{~m}$ distance from the plants. Before each set of measurements, background temperature was determined by measuring the temperature of a crumpled sheet of aluminium foil in a similar position to the leaves of interest with the emissivity set at 1.0 following the methodology described by Costa et al. (2013). Thermal images were analysed with the software FLIR Tools (FLIR Systems, Inc.). The temperature of each plant was determined from the temperature of five leaves using the function "area". Visible images (RGB) were collected to complement the analysis of thermal images.

\section{Gas exchange and chlorophyll $a$ fluorescence steady-state measurements}

Parallel measurements of photosynthetic gas exchange and chlorophyll $a$ fluorescence were performed in a non-detached fully expanded leaf from each plant using a gas exchange system (IRGA LCpro+, ADC BioScientific) combined with a chlorophyll fluorescence imaging system (Imaging-PAM Chlorophyll Fluorometer M-series Mini version, Heinz Walz GmbH). Control air temperature was set to $25^{\circ} \mathrm{C}$, PPFD at the leaf level set to $226 \mu \mathrm{mol} \mathrm{m} \mathrm{m}^{-2}$ and the $\mathrm{CO}_{2}$ concentration in the leaf chamber set to $400 \mu \mathrm{mol} \mathrm{CO} \mathrm{Col}^{-1}$ air allowing the leaf to reach steady-state assimilation rate (A) and stomatal conductance (gs). A and gs were calculated by the LCpro+ software according to von Caemmerer and Farquhar (1981). Chlorophyll $a$ steady-state fluorescence was analysed using the Imaging Win analytical software (Heinz Walz GmbH). PSII effective quantum yield ( PPSII) was obtained according to Genty et al. (1989), photochemical (qP) and non-photochemical (qN) quenching were calculated according to Oxborough and Baker (1997) and total non-photochemical fluorescence quenching (NPQ) was calculated using the Stern-Volmer approach (Krause and Jahns 2007). Electron transport rate $($ ETR $)$ was then calculated as: $E T R=0.5 \Phi$ PSII $\times$ PPFD $\times$ abs. Absorptivity $($ abs $)$ was measured for each leaf before the chlorophyll $a$ fluorescence measurement.

\section{Chlorophyll $a$ fluorescence induction}


The kinetics of the rapid fluorescence induction rise was recorded on fully expanded dark-adapted leaves (10 minutes) exposed to a saturating light pulse $\left(3500 \mu \mathrm{mol} \mathrm{m} \mathrm{m}^{-2} \mathrm{~s}^{-1}\right)$ for 1 second to obtain the OJIP Chl $a$ fluorescence transient rise (Handy PEA, Hansatech Instruments). Fluorescence parameters derived from the extracted data, namely specific energy fluxes per QA-reducing PSII reaction center and photosynthetic performance indexes were calculated according to Strasser and collaborators (Strasser et al. 2004, Tsimilli-Michael and Strasser 2008) with the nomenclature presented in Stirbet and Govindjee (2011).

\section{Antioxidant capacity}

Antioxidant metabolites were extracted from frozen leaf samples $(0.1-0.3 \mathrm{~g} \mathrm{FW})$ by homogenisation in pure methanol with $1.4 \mathrm{~mm}$ zirconium oxide beads (Precellys) in a tissue homogenizer (Precellys Evolution, Precellys) and then centrifuged at $20000 \mathrm{~g}$ for $5 \mathrm{~min}$. Trolox equivalents antioxidant capacity (TEAC) and ferric reducing antioxidant power (FRAP) were measured in the supernatant using a 96-well microtiter plate. TEAC was determined by the reaction of the sample supernatant and 2,2'Azino-bis (3-ethylbenzothiazoline-6-sulfonic acid) diammonium salt (ABTS), solution 1:20 in phosphate buffer $\mathrm{pH} 7.4$ (0.7-0.8 optical density). The reaction mixtures were incubated $6 \mathrm{~min}$ at room temperature before measuring absorbance at $734 \mathrm{~nm}$ (ELx808, BioTek Instruments, Inc.). 6-hydroxy2,5,7,8-tetramethylchroman-2-carboxylic acid (Trolox) standards $(0-0.8 \mathrm{mM}$ in $96 \%$ ethanol) were measured alongside the samples and used to prepare the respective calibration curve. FRAP was measured by the reaction of the sample supernatant with a solution consisting of $0.3 \mathrm{mM}$ acetate buffer, $10 \mathrm{mM}$ 2,4,6-tripyridyl-s-triazine (TPTZ) and $20 \mathrm{mM} \mathrm{FeCl}_{3}$. The reaction mixtures were incubated 4 $\mathrm{min}$ at room temperature before measuring the absorbance at 593nm (ELx808, BioTek Instruments Inc.). $\mathrm{FeSO}_{4}$ standards $(0-1.0 \mathrm{mM})$ in $\mathrm{ddH}_{2} \mathrm{O}$ were measured alongside the samples and used to prepare the respective calibration curves. Samples and standards were measured in triplicate alongside blanks containing no sample.

\section{Rubisco activity}

Rubisco was extracted from the leaves by grinding frozen samples $(0.1-0.3 \mathrm{~g} \mathrm{FW})$ in a cold mortar with quartz sand, $1 \%(\mathrm{w} / \mathrm{v})$ insoluble polyvinylpyrrolidone (PVP), ice-cold extraction medium (1/10 FW per $\mathrm{mL}$ ) containing $50 \mathrm{mM}$ Bicine-KOH pH 8.0, $1 \mathrm{mM}$ ethylenediaminetetraacetic acid (EDTA), 5\% (w/v) polyvinylpyrrolidone (PVP25000), 6\% polyethylene glycol ( $\left.\mathrm{PEG}_{4000}\right), 10 \mathrm{mM}$ 1,4-dithiothreitol (DTT), $50 \mathrm{mM} \beta$-mercaptoethanol and 1\% (v/v) protease inhibitor cocktail for plant extracts (Sigma-Aldrich), adapted from Carmo-Silva et al. (2010). Leaf extracts were then centrifuged at $14000 \mathrm{~g}$ and $4^{\circ} \mathrm{C}$ for 5 min. The supernatant was kept at $4^{\circ} \mathrm{C}$ and used immediately for measurement of Rubisco activities by the incorporation of ${ }^{14} \mathrm{CO}_{2}$ into acid-stable products at 25 and $38^{\circ} \mathrm{C}$, following the protocol described in Parry et al. (1997) with modifications. The reaction mixture contained $100 \mathrm{mM}$ Bicine-NaOH pH 8.2, $40 \mathrm{mM} \mathrm{MgCl} 2,10 \mathrm{mM} \mathrm{NaH}^{14} \mathrm{CO}_{3}\left(7.4 \mathrm{kBq} \mu \mathrm{mol}^{-1}\right)$ and $0.4 \mathrm{mM}$ ribulose 1,5-bisphosphate( $\left.\mathrm{Ru} \mathrm{BP}\right)$. 
Rubisco initial activity (Vi) was determined by adding the supernatant to the mixture and stopping the reaction after 60-180s with $10 \mathrm{M} \mathrm{HCOOH}$. Total activity (Vt) was measured after incubating the same volume of extract for $3 \mathrm{~min}$ with all the reaction mixture components except RuBP, to allow carbamylation of all the Rubisco available catalytic sites. The reaction was then started by adding RuBP and stopped as above. All measurements were carried out in triplicate and control reactions were quenched with $\mathrm{HCOOH}$ prior to the addition of RuBP. The mixtures were completely dried at $70^{\circ} \mathrm{C}$ overnight and the residues re-hydrated in $0.5 \mathrm{~mL} \mathrm{ddH}_{2} \mathrm{O}$, then mixed with $5 \mathrm{~mL}$ scintillation cocktail (Ultima Gold, Perkin-Elmer). Radioactivity due to ${ }^{14} \mathrm{C}$ incorporation in the acid-stable products was measured by liquid scintillation counting (LS7800, Beckman). The activation state of Rubisco was calculated as the ratio $\mathrm{Vi} / \mathrm{Vt} \times 100$. Total soluble protein $(\mathrm{TSP})$ content was determined according to the Bradford method (Bradford 1976) using BSA Fraction V as standard protein.

\section{Invertase activity}

Cytosolic invertase (CytInv) and vacuolar invertase (VacInv) were extracted from the leaves by grinding frozen samples (0.1-0.3 g FW) in a cold mortar with quartz sand, $1 \%(\mathrm{w} / \mathrm{v}) \mathrm{PVPP}$, ice-cold extraction medium containing $40 \mathrm{mM}$ TRIS- $\mathrm{HCl} \mathrm{pH} 7.6,3 \mathrm{mM} \mathrm{MgCl}_{2}, 1 \mathrm{mM}$ EDTA, $0.1 \mathrm{mM}$ phenylmethylsulfonyl fluoride (PMSF), $1 \mathrm{mM}$ benzamidine, $14 \mathrm{mM} \beta$-mercaptoethanol, $24 \mu \mathrm{M}$ nicotinamide adenine dinucleotide phosphate $\left(\mathrm{NADP}^{+}\right)$, according to Jammer et al. (2015), with modifications. Leaf extracts were then centrifuged at $20000 \mathrm{~g}$ for $10 \mathrm{~min}$ at $4^{\circ} \mathrm{C}$. The supernatant was kept at $4^{\circ} \mathrm{C}$ and dialysed overnight with $20 \mathrm{mM}$ potassium phosphate buffer $\mathrm{pH} 7.4$ at $4^{\circ} \mathrm{C}$ in a dark room. Extracts were aliquoted, frozen in liquid nitrogen and stored at $-20^{\circ} \mathrm{C}$. The activities were measured in thawed samples using 96-well microtiter plates. Reaction mixtures containing $10 \mathrm{mM}$ sucrose and dialysed protein extract were incubated for $30 \mathrm{~min}$ at $37^{\circ} \mathrm{C}$, cooled for $5 \mathrm{~min}$ on ice to stop the reaction, and then incubated for $30 \mathrm{~min}$ at room temperature with GOD-POD reagent $\left(10 \mathrm{U} \mathrm{mL}^{-1}\right.$ of Glucose oxidase from Aspergillus niger (GOD), $0.8 \mathrm{U} \mathrm{mL}^{-1}$ peroxidase from horseradish (POD) and $0.8 \mathrm{mg} \mathrm{mL}^{-1}$ ABTS in $0.1 \mathrm{M}$ potassium phosphate buffer ( $\mathrm{pH}$ 7.0). The amount of liberated glucose was determined by measurement of absorbance at $405 \mathrm{~nm}$ at $30^{\circ} \mathrm{C}$ (ELx808, BioTek Instruments Inc.). Glucose standards $(0-50 \mathrm{nmol})$ were measured alongside the samples and used to prepare the respective calibration curves. All measurements were carried out in triplicate alongside blanks containing no sucrose. TSP content was determined according to the Bradford method (Bradford 1976) using BSA Fraction V as standard protein.

\section{Statistical analysis}

The statistical significance of trait variation was tested by factorial ANOVA, with cultivars, irrigation and temperature regimes as fixed factors. Post-hoc comparison between treatments was performed with Duncan test $(\mathrm{P}<0.05)$ using IBM SPSS Statistics, Version 25 (IBM, USA). Multivariate analysis was performed with MixOmics R package (Rohart et al. 2017) using Rstudio software. 


\section{Leaf and soil water relations under drought and high temperatures}

260 To characterise the leaf and soil water status of Sokoll and Paragon plants, leaf and soil relative water content (LRWC and SRWC, respectively) and leaf water potential (LWP) were estimated at the end of each experimental condition (Table 1). Well-watered (WW) plants presented leaf relative water content (LRWC) and leaf water potential (LWP) around or above $80 \%$ and $-1 \mathrm{M} \mathrm{Pa}$, respectively, suggesting good cellular hydration. On the other hand, water deficit (WD) conditions led to a decrease in LRWC and LWP values (lower than 70\% and $-1 \mathrm{MPa}$, respectively), revealing a reduction in hydration and a considerable driving force for water movement through the plant. Under $\mathrm{WD} 25^{\circ} \mathrm{C}$, Paragon presented higher LRWC than Sokoll, even though no significant differences were found for LWP and soil relative water content (SRWC), showing the capacity of this genotype to maintain cellular hydration under these conditions. The canopy temperature (Tcanopy) increased in both cultivars when subject to high temperatures. Under $\mathrm{WW} 38^{\circ} \mathrm{C}$, Tcanopy was significantly lower in Sokoll compared to Paragon, indicating the ability of Sokoll to avoid heat and maintain optimal cell temperature. No differences were observed between the genotypes when subjected to WD $38^{\circ} \mathrm{C}$, the observed LRWC under $50 \%$ and low LWP indicate severe drought stress, and Tcanopy was also highest in these plants.

\section{Effects of drought and high temperature on photosynthesis}

WD plants had significantly lower net photosynthesis assimilation rate (A), stomatal conductance (gs) and electron transport rate (ETR) compared to WW plants, except for Paragon at $25^{\circ} \mathrm{C}$ (Fig. 1A-C). Steady-state photosynthetic gas-exchanges were comparable for both genotypes under WW conditions. A strong positive relationship between A and gs was observed $(r=0.914, P<0.0001$ and $r=0.974$ $P<0.0001$, Paragon and Sokoll respectively, Table S1), suggesting a possible stomatal limitation to photosynthesis, and between A and ETR ( $r=0.966, P<0.0001$ and $r=0.797, P<0.0001$, Table S1), suggesting limitations at the photosystems level.

Effect of water deficit and high temperatures on Rubisco in vivo activities measured at control and high temperatures

To verify if the limitations in the carbon fixation found under stress conditions were a result of an imbalance in the Calvin-Benson-Bassham cycle, the in vivo Rubisco activity was assessed at the two growth temperatures. When Rubisco activity was measured at $25^{\circ} \mathrm{C}$, the initial and total velocities decreased significantly under WD $\left(\mathrm{WD} 25^{\circ} \mathrm{C}\right.$ and $\mathrm{WD} 38^{\circ} \mathrm{C}$ ) and elevated temperatures (WW3 $38^{\circ} \mathrm{C}$ ) (Fig. 2A,B). However, the activation state of Rubisco remained largely unchanged between the various conditions (Fig. 2C). When Rubisco assays were performed at $38^{\circ} \mathrm{C}$, activities were higher compared to measurements at $25^{\circ} \mathrm{C}$, although the increase of initial velocity was higher than in total velocity (Fig. 
irrigation regimes. No significant differences were observed in Rubisco activation state when measured at this temperature (Fig. 2F). The lack of differences in net photosynthetic assimilation rate of WW $38^{\circ} \mathrm{C}$ plants (Fig. 1A) would indicate that even the reduced level of Rubisco activity in these plants $(\sim 10 \mu \mathrm{mol}$ $\mathrm{CO}_{2} \mathrm{~m}^{-2} \mathrm{~s}^{-1}$, Fig. S1D) is sufficient to support photosynthesis at the growth light levels (PPFD $<300$ $\mu \mathrm{mol}$ photons $\mathrm{m}^{-2} \mathrm{~s}^{-1}$ ).

\section{Effect of water deficit and high temperatures on the antioxidant capacity and chlorophyll $a$ fluorescence}

To analyse how both genotypes cope with possibly harmful consequences caused by energy excess under stress, chlorophyll $a$ fluorescence and two dissipation mechanisms, ROS scavenging and nonphotochemical dissipation, were quantified. A decrease of photochemical quenching ( $\mathrm{qP}$ ) was observed in Sokoll WD25 $5^{\circ} \mathrm{C}$ and in both genotypes at WD $38^{\circ} \mathrm{C}$ (Fig. 3A-B). Under the same conditions, nonphotochemical quenching (qN, NPQ) increased (Fig. 3 C-D). Moreover, the two genotypes showed an increase in the antioxidant capacity (FRAP and TEAC) under drought at both temperatures (Fig. $3 \mathrm{E}$, F). In order to thoroughly understand how the different biochemical processes in the photosystems are affected by stress conditions, the chlorophyll $a$ kinetic parameters were correlated with the antioxidant capacity and NPQ, and ETR (Fig. 4). A positive correlation was observed between the antioxidant capacity and NPQ, as well as an inverse correlation to ETR. In all conditions, Sokoll showed a stronger correlation between the number of electron carriers per electron transport chain $\left(\mathrm{S}_{\mathrm{m}}\right)$ and ETR than Paragon. The strength of the correlation between energy fluxes $\left(\mathrm{J}^{\mathrm{ABS}}, \mathrm{J}^{\mathrm{DI}}, \mathrm{J}_{\mathrm{o}}{ }^{\mathrm{ET} 2}\right.$ and $\left.\mathrm{J}_{\mathrm{o}}{ }^{\mathrm{RE} 1}\right)$, ETR and NPQ changed for both genotypes under WD (Fig. 4A,C). This was particularly the case in Paragon in $\mathrm{WD} 38^{\circ} \mathrm{C}$ (Figs $4 \mathrm{C}, \mathrm{S} 2$ and Table S2), supported by the increase of $\mathrm{J}^{\mathrm{ABS}}, \mathrm{J}^{\mathrm{DI}}$ and $\mathrm{J}_{\mathrm{o}}{ }^{\mathrm{RE} 1}$ to control conditions. In Sokoll the positive correlation between ETR and both electron transport fluxes $\left(\mathrm{J}_{\mathrm{o}}{ }^{\mathrm{ET} 2}\right.$ and $\mathrm{J}_{\mathrm{o}}^{\mathrm{RE1}}$, Fig. $4 \mathrm{C}$ ) indicated a decrease of electron transport rate on the entire flux until photosystem I.

\section{Recovery from high temperatures conditions}

Following 5 days of exposure to high temperatures and/or drought, wheat plants were allowed to recover for 7 days (at $25^{\circ} \mathrm{C}$ and $\mathrm{WW}$ ) and their photosynthetic performance was compared by measuring chlorophyll $a$ fluorescence, net photosynthetic assimilation and stomatal conductance. Even though no differences were detected on the fraction of open PSII reaction centres (qP, Fig. 5A,B), a significant increase on the non-photochemical quenching was observed relative to control (qN, NPQ, Fig. 5A,C,D). The increase in NPQ was only accompanied by a decrease in the electron transport rate of Sokoll recovering from $\mathrm{WD} 38^{\circ} \mathrm{C}$ (Fig. 5E). Paragon presented higher LRWC and LWP when recovering from $\mathrm{WD} 38^{\circ} \mathrm{C}$ than Sokoll (Table 1), even though no significant differences were found, indicating a higher capacity of this genotype to return to control cellular hydration and recover the driving force for water movement through the plant. Slower recovery of Sokoll ETR and higher NPQ suggest that WD is promoting photoinhibition in Sokoll. The photosynthetic assimilation rate and stomatal conductance 
(Fig. 5F,G) increased in Paragon plants recovered after growing at $38^{\circ} \mathrm{C}$ in $\mathrm{WW}$ and $\mathrm{WD}$ conditions relative to control. However, in Sokoll, the photosynthetic assimilation rate decreased significantly in recovery from $\mathrm{WD} 38^{\circ} \mathrm{C}$ and gs decreased when recovering from both conditions. All parameters reflecting the photosynthetic capacity revealed a better recovery from $\mathrm{WD} 38^{\circ} \mathrm{C}$ in Paragon compared to Sokoll. Once again, results suggest that stomatal conductance impairment and recovery are a limiting factor for photosynthesis rate under water deficit and high temperature.

\section{Invertase in vivo activities under water deficit and high temperatures}

To verify if other sources of energy were used to cope with stress besides the direct usage of photoassimilates, the activity of invertases isoenzymes (located in the cytosol and vacuole) were measured. Results showed that the activity of vacINV was higher in Paragon for all the conditions compared to Sokoll (Fig. 6A). However, modulation of cytINV was observed according to different stress conditions (Fig. 6B): the cytINV activity increased in plants growing at $38^{\circ} \mathrm{C}$ with an interesting difference between $\mathrm{WD} 38^{\circ} \mathrm{C}$ to $\mathrm{WW} 38^{\circ} \mathrm{C}$ and $\mathrm{WW} 25^{\circ} \mathrm{C}$ in Paragon. Even though the CytINV activity slightly increased, no significant differences were found for all conditions in Sokoll (Fig 6B). Overall, in Paragon, cytINV was negatively correlated to the assimilation rate $(r=-0.774, P<0.0001$, Table S1). Together with the previous results that showed a better recovery of this genotype after the combination of water deficit and high temperature, these data suggest that an increase of sucrose catabolism, when the production of photosynthetic assimilates decreases, improved wheat recovery from stress conditions.

\section{Discussion}

Two wheat cultivars, Paragon and Sokoll, were studied for their ability to withstand water deficit and high temperatures, in isolation or in combination. Paragon is a traditional UK spring wheat elite cultivar (Moore 2015), while Sokoll is a synthetic-derived cultivar developed by the International Maize and Wheat Improvement Centre (CIMMYT, Mexico), known to show good productivity under elevated temperatures (Solís Moya and Camacho Casas 2016). As these genotypes are adapted to distinct environmental conditions, it is of relevance to determine which factors are responsible for their photosynthetic performance. Therefore, the present study aimed to first characterise the photosynthetic limitations of the two genotypes under water deficit and/or high temperature and then to assess photosynthetic recovery from high temperature in the absence or presence of drought. To achieve this goal, Paragon and Sokoll were compared using several established parameters, namely net assimilation rate, stomatal conductance, Rubisco and invertase in vitro activities, antioxidant capacity and chlorophyll $a$ fluorescence.

Under increased temperatures a natural heat avoidance strategy of plants is to decrease leaf temperature through increased transpiration (Carmo-Silva et al. 2012, Zandalinas et al. 2018). Albeit at 
$25^{\circ} \mathrm{C}$, both genotypes showed a mean leaf temperature slightly higher than the atmospheric temperature $\left(\right.$ Paragon $=26.87^{\circ} \mathrm{C}$; Sokoll $\left.=26.33^{\circ} \mathrm{C}\right)$, when subjected to $38^{\circ} \mathrm{C}$ both genotypes showed a decrease of leaf temperature relative to atmospheric temperature, which was statistically significant in Sokoll at WW $38^{\circ} \mathrm{C}$ (Table 1). Additionally, both genotypes maintained similar photosynthetic assimilation and electron transport rates compared to control conditions (Fig. 1A,C). However, in vitro Rubisco activity decreased more than 10-fold (Fig. 2), in agreement with previous reports (Galmés et al. 2013, Perdomo et al. 2016, 2017). The maintenance of assimilation rates despite this abrupt decline in Rubisco activity can be explained by the increase in catalytic rate under increased temperature. When measured at $38^{\circ} \mathrm{C}$, the initial activity was 5 times higher than when measured at $25^{\circ} \mathrm{C}$ (Fig. 2A,D) and showed rates comparable to the rates of photosynthesis in the same plants. In vivo, the Rubisco chaperone (RUBISCO ACTIVASE, RCA) helps to overcome possible dead-end inhibition of Rubisco by promoting ATPdependent conformational changes at the closed sites of Rubisco (Feller, Crafts-Brandner and Salvucci, 1998, Crafts-Brandner and Salvucci, 2000, Salvucci and Crafts-Brandner, 2004) and may contribute to sustaining Rubisco activities at adequate levels to support carbon assimilation (Perdomo et al. 2017). Under our experimental conditions and without water restrictions, photosynthesis occurred at sufficient rates to supply carbon for cellular growth and metabolic energy.

Despite no direct impact of high temperatures was found on photosynthetic assimilation, stomatal conductance and electron transport rate, and in spite of the better performance of Paragon at $\mathrm{WD} 25^{\circ} \mathrm{C}$, no differences between genotypes were observed at $\mathrm{WD} 38^{\circ} \mathrm{C}$, since these parameters significantly decreased in both Paragon and Sokoll (Fig. 1A,C). These results illustrate that when combined, water deficit and high temperatures have a synergistic effect, both genotypes showed severe leaf dehydration (LRWC> 50\%, Table 1) and a serious reduction of stomatal conductance (less than $15 \%$ of control values, Fig. 1B). Under such stress conditions, photosynthesis no longer provides a source of carbon and other mechanisms are required to enable plants' intense reprogramming effort to acclimatise, survive and, mostly, to recover physiological functions after re-watering. Various stress conditions result in the coordinated regulation of both source - sink relations and direct defence responses (Roitsch 1999, Jan et al. 2019, Kosar et al. 2020). Notably, the activities of the different invertase isoenzymes are affected by drought and heat stress (Albacete et al. 2011). Paragon recovered faster from high temperatures and water deficit conditions (Fig. 5) presented higher activity of cytINV and slightly higher activity of vacINV (Fig. 6A,B). These results are suggesting that genotypes with high capacity to hydrolyse sucrose recover faster from episodes of high temperatures combined with drought and therefore reduce the impact of climate fluctuation in yield. Marques da Silva and Arrabaça (2004), in the $\mathrm{C}_{4}$ grass Setaria sphacelata, found that the higher amount of soluble carbohydrates and $\mathrm{t}$ lower amount of starch in leaves exposed to long-term water deficit played a minor role on the osmoregulation against desiccation, suggesting that high availability of hexoses is mainly due to changes on the sucrose metabolism to support other cellular functions. Pinheiro and Chaves (2011) also suggested a connection between cytINV and ABA, sucrose, starch, and ROS metabolism in response 
to acute drought stress. Higher activity of vacINV has been reported in maize leaves under water deprivation conditions (Pelleschi et al. 1997, Trouverie et al. 2003), although in sugarcane (Wang et al. 2017), cytINV was also shown to play a more prominent role than vacINV under abiotic stress. In barley, activities of both vacINV and cytINV were repressed after a heat stress episode (Antonio CuestaSeijo et al. 2019). In tomato, ectopic expression of cell wall invertases resulted in drought tolerance that was accompanied by also changes in cytINV and vacINV (Albacete et al. 2015). Barratt et al. (2009) demonstrated that cytINV may be the primary route by which carbon from sucrose is supplied to nonphotosynthetic tissues in Arabidopsis, suggesting, in concordance to our results, that it would grant a source of carbon to feed cellular functions when photosynthesis is impaired. Secchi and Zwieniecki $(2012,2016)$ suggested that, under severe drought, high levels of sugar accumulation and invertase activity could prime the xylem for the accelerated restoration of xylem function upon return to hydrated conditions. The authors proposed that the reduction of stomatal conductance and embolism reduces the transpiration flow, subsequently changing the balance of carbohydrate fluxes in xylem instigating the accumulation of sucrose in the apoplast. That mechanism can trigger a cellular stress response promoting starch degradation, leading to the increase of cellular soluble sugar concentration and membrane sucrose gradient. The suggested model is in accordance to our results, Paragon showed high activity of invertases under severe drought (WD $38^{\circ} \mathrm{C}$, Fig. 6) and the resuming high osmotic level could help xylem embolism refilling and the recovery of transport. When water is delivered from roots, the fast recovery of transpiration could consequently help to explain the faster recovery of photosynthesis, leaf water potential and leaf hydration (Fig. 5 and Table 1). The observed evidence highlighted the role of sucrolytic enzymes in the supply of carbon from sucrose needed to the massive metabolic reorganization employed to tolerate stress, helping plants to recover faster and being less affected by heat and water deficit episodes.

In the present study, $\mathrm{WD} 38^{\circ} \mathrm{C}$ affected the photochemical capacity in both genotypes, increasing NPQ and qN (Fig. 3B,C) and decreasing qP (Fig. 3A), followed by a decrease of ETR (Fig. 1C). Generally, in higher plants, $\mathrm{qE}$ is assumed as the major component of $\mathrm{qN}$, as a short time adaptation to deal with the overproduction of ATP and NADPH and the accumulation of protons in the thylakoid lumen when $\mathrm{CO}_{2}$ fixation decreases (Krause and Jahns 2007, Takahashi and Murata 2008). Generally, if the energy dissipation mechanisms (qE, qT) and ROS detoxification fail, oxidative damage occurs, leading to photoinhibition (Murata et al. 2007, Yamamoto 2016). The increase in the ROS scavenging activity was observed in both genotypes under WD $38^{\circ} \mathrm{C}$ (Fig. 3E,F). In Paragon, an increase of the absorbed photon flux $\left(\mathrm{J}^{\mathrm{ABS}}\right)$ was not followed by an increase in the maximum trapped flux $\left(\mathrm{J}_{\mathrm{o}}{ }^{\mathrm{TR}}\right)$ and the electron transport from $\mathrm{Q}_{\mathrm{A}}$ to $\mathrm{Q}_{\mathrm{B}}\left(\mathrm{J}_{\mathrm{O}}{ }^{\mathrm{ET} 2}\right)$, probably because of the observed increase in the dissipated energy flux ( $\mathrm{J}^{\mathrm{DI}}$ ) (Figs 4, S2 and Table S2), which avoid the overreduction of the electron transport chain. Additionally, the photochemical function of this genotype fully recovered upon stress release, as shown by the recovery of qP and ETR to values similar to control conditions (Fig. 5B,E). The increase in dissipated energy flux may be related to a photoprotective mechanism based on the aggregation and 
detachment of the light-harvesting complex II (LHCII) from the reaction center of PSII (Ruban et al.

442 2012; Ruban 2016). In higher plants, LHCII aggregates are common sites of energy dissipation

443 facilitated by PsbS (qE) or induced by redox-controlled LHCII phosphorylation (qT) (Minagawa 2011),

444 active in plants under $\mathrm{CO}_{2}$ starvation and heat stress (Šiffel and Vácha 1998, Šiffel and Braunová 1999,

445 Tang et al. 2007). On the other hand, in Sokoll, the reduction of ETR highly correlates to the decrease

446 of both electron transport fluxes (JoET2 and JoRE1, Fig. $4 \mathrm{WD} 38^{\circ} \mathrm{C}$ ), and despite the full recovery of

447 qP, NPQ levels remained at high levels and ETR stayed below control condition, indicating slower and

448 limited recovery (Fig. 5). Chlorophyll fluorescence parameters clearly indicate differences in photoprotection when both genotypes were subjected to $\mathrm{WD} 38^{\circ} \mathrm{C}$ and faster recovery of Paragon after stress relief.

Modulation of the cytosolic invertase was observed and suggests a relationship between an increase of CytINV activity under stress and the recovery of photosynthesis upon high temperatures and water deficit conditions. Upon water shortage and elevated temperatures, when photosynthetic performance and growth priorities are altered, optimization of sucrose export and utilization in conjunction with increased photoprotection of the electron transport machinery could contribute to the recovery of photosynthetic capacity, and consequently to reduce yield fluctuations under climate change. The integration of cell physiological phenotyping via the semi-highthroughput determination of enzyme activity signatures (Jammer et al. 2015) with ecophysiological measurements proved to be a powerful holistic phenomics approach (Großkinsky et al. 2015).

\section{Author contributions}

P.M.P.C. planned and carried out the experiments, analysed and interpreted the results. E.C.S. and J.M.S. contributed to the interpretation of the results and supervised the research. A.B.S. and T.R. provided critical feedback. P.M.P.C. took the lead in writing the manuscript. All authors discussed the results and contributed to the final manuscript.

Acknowledgments - Financial support by UIDB/04046/2020 and UIDP/04046/2020 Centre grants from FCT (BioISI), FCT research project INTERPHENO (PTDC/ASP-PLA/28726/2017) and Access to Research Infrastructures activity in the Horizon2020 Programme of the EU (EPPN2020 Grant Agreement 731013) is gratefully acknowledged. T.R. would like to acknowledge support by the Ministry of Education, Youth and Sports of CR within the National Sustainability Program I (NPU I), grant number LO1415. E.C.S. acknowledges funding from the UK Biotechnology and Biological Sciences Research Council (BBSRC) under grant number BB/L011786/1. P.M.P.C. acknowledges FCT (Portugal) for the financial support via a fellowship from BioSys PhD program PD65-2012 (Ref SFRH/PD/BD/130973/2017). We would like to thank Gemma Molero (CIMMYT) for the supply of Sokoll seed, Hamilton Chiango for help with plant growth and Ricardo Cruz Carvalho for the support in leaf water potential measurements. 
The data that support the findings of this study are available from the corresponding author upon request and data supporting findings of this study are available in the supplementary material of this article.

\section{References}

483

Albacete A, Cantero-Navarro E, Großkinsky DK, Roitsch T (2015) Ectopic overexpression of the cell wall invertase gene CIN1 leads to dehydration avoidance in tomato. J Exp Bot 66: 863-878

Albacete A, Großkinsky DK, Roitsch T (2011) Trick and treat: a review on the function and regulation of plant invertases in the abiotic stress response. Phyton Annales Rei Botanicae 50: 181-204

Allakhverdiev SI, Kreslavski VD, Klimov VV, Los DA, Carpentier R, Mohanty P (2008) Heat stress: An overview of molecular responses in photosynthesis. Photosynth Res 98: 541-550

Cuesta-Seijo AJ, De Porcellinis AJ, Valente AH, Striebeck A, Voss C, Marri L, Hansson A, Jansson AM, Dinesen MH, Fangel JU, Harholt J, Popovic M, Thieme M, Hochmuth A, Zeeman SC, Mikkelsen TN, Jørgensen RB, Roitsch T, Lindberg MB, Braumann I (2019) Amylopectin Chain Length Dynamics and Activity Signatures of Key Carbon Metabolic Enzymes Highlight Early Maturation as Culprit for Yield Reduction of Barley Endosperm Starch after Heat Stress. Plant Cell Physiol 60: 2692-2706

Aronsson H, Schöttler MA, Kelly AA, Sundqvist C, Dörmann P, Karim S, Jarvis P (2008) Monogalactosyldiacylglycerol deficiency in Arabidopsis affects pigment composition in the prolamellar body and impairs thylakoid membrane energization and photoprotection in leaves. Plant Physiol 148: 580-592

Barratt DHP, Derbyshire P, Findlay K, Pike M, Wellner N, Lunn J, Feil R, Simpson C, Maule AJ, Smith AM, (2009) Normal growth of Arabidopsis requires cytosolic invertase but not sucrose synthase. Proc Natl Acad Sci USA 106: 13124-13129

Begum N, Ahanger MA, Su Y, Lei Y, Mustafa NSA, Ahmad P, Zhang L (2019) Improved drought tolerance by AMF inoculation in maize (Zea mays) involves physiological and biochemical implications. Plants 8: 579

Bradford MM (1976) A rapid and sensitive method for the quantitation of microgram quantities of protein utilizing the principle of protein-dye binding. Anal Biochem 72: 248-254

Carmo-Silva AE, Gore MA, Andrade-Sanchez P, French NA, Hunsaker DJ, Salvucci ME (2012) Decreased CO2 availability and inactivation of Rubisco limit photosynthesis in cotton plants under heat and drought stress in the field. Environ Exp Bot 83: 1-11

Carmo-Silva AE, Keys AJ, Andralojc PJ, Powers SJ, Arrabaça MC, Parry MAJ (2010) Rubisco activities, properties, and regulation in three different $\mathrm{C} 4$ grasses under drought. J Exp Bot 61: 2355-2366

Carmo-Silva E, Scales JC, Madgwick PJ, Parry MAJ (2015) Optimizing Rubisco and its regulation for 
greater resource use efficiency. Plant, Cell Environ 38: 1817-1832

515

516

517

518

519

520

521

522

523

524

525

526

527

528

529

530

531

532

533

534

535

536

537

538

539

540

541

542

543

544

545

546

547

548

549

550

Čatský J (1960) Determination of water deficit in disks cut out from leaf blades. Biol Plant 2:76-78

Chaves MM, Maroco JP, Pereira JS (2003) Understanding plant responses to drought - from genes to the whole plant. Funct Plant Biol 30: 239

Chen YE, Liu WJ, Su YQ, Cui JM, Zhang ZW, Yuan M, Zhang HY, Yuan S (2016) Different response of photosystem II to short and long-term drought stress in Arabidopsis thaliana. Physiol Plant 158: $225-235$

Costa JM, Grant OM, Chaves MM (2013) Thermography to explore plant-environment interactions. J Exp Bot 64: 3937-3949

Crafts-Brandner SJ, Salvucci ME (2000) Rubisco activase constrains the photosynthetic potential of leaves at high temperature and $\mathrm{CO}^{2}$. Proc Natl Acad Sci USA 97: 13430-13435

Degen GE, Worrall D, Carmo-Silva E (2020) An isoleucine residue acts as a thermal and regulatory switch in wheat Rubisco activase. Plant J 103: 742-751

Deryng D, Conway D, Ramankutty N, Price J, Warren R (2014) Global crop yield response to extreme heat stress under multiple climate change futures. Environ Res Lett 9: 034011

Duque AS, de Almeida AM, Bernardes da Silva A, Marques da Silva J, Farinha PA, Santos D, Fevereiro P, Araújo SS (2013) Abiotic Stress Responses in Plants: Unraveling the Complexity of Genes and Networks to Survive. InTech 3: 49-101

FAOSTAT Statistical Database; 2017; Food and Agriculture Organization of the United Nations; Rome Feller U, Crafts-Brandner SJ, Salvucci ME (1998) Moderately High Temperatures Inhibit Ribulose1,5-Bisphosphate Carboxylase/Oxygenase (Rubisco) Activase-Mediated Activation of Rubisco. Plant Physiol 116: 539-46

Figueroa CM, Lunn JE (2016) A tale of two sugars: Trehalose 6-phosphate and sucrose. Plant Physiol 172: 7-27

Foyer CH (2018) Reactive oxygen species, oxidative signaling and the regulation of photosynthesis. Environ Exp Bot 154: 134-142

Galmés J, Aranjuelo I, Medrano H, Flexas J (2013) Variation in Rubisco content and activity under variable climatic factors. Photosynth. Res 117: 73-90

Genty B, Briantais JM, Baker NR (1989) The relationship between the quantum yield of photosynthetic electron transport and quenching of chlorophyll fluorescence. Biochim Biophys Acta 990:87-92

Gounaris K, Brain APR, Quinn PJ, Williams WP (1983) Structural and functional changes associated with heat-induced phase-separations of non-bilayer lipids in chloroplast thylakoid membranes. FEBS Letters 153: 47-52

Großkinsky DK, Svensgaard J, Christensen S, Roitsch T (2015) Plant phenomics and the need for physiological phenotyping across scales to narrow the genotype-to-phenotype knowledge gap. $\mathrm{J}$ Exp Bot 66: 5429-40

Heckathorn SA, Coleman JS, Hallberg RL (1998) Recovery of net $\mathrm{CO}^{2}$ assimilation after heat stress is 
correlated with recovery of oxygen-evolving-complex proteins in Zea mays L. Photosynthetica 34: $13-20$

Jammer A, Gasperl A, Luschin-Ebengreuth N, Heyneke E, Chu H, Cantero-Navarro E, Großkinsky DK, Albacete AA, Stabentheiner E, Franzaring J, Fangmeier A, Graaff E, Roitsch T (2015) Simple and robust determination of the activity signature of key carbohydrate metabolism enzymes for physiological phenotyping in model and crop plants. J Exp Bot 66: 5531-5542

Jan S, Abbas N, Ashraf M, Ahmad P (2019) Roles of potential plant hormones and transcription factors in controlling leaf senescence and drought tolerance. Protoplasma 256: 313-329

Kamata T, Hiramoto H, Morita N, Shen JR, Mann NH, Yamamoto Y (2005) Quality control of photosystem II: An FtsH protease plays an essential role in the turnover of the reaction center D1 protein in Synechocystis PCC 6803 under heat stress as well as light stress conditions. Photochem Photobiol Sci 4: 983-990

Komayama K, Khatoon M, Takenaka D, Horie J, Yamashita A, Yoshioka M, Nakayama Y, Yoshida M, Ohira S, Morita N, Velitchkova M, Enami I, Yamamoto Y (2007) Quality control of Photosystem II: Cleavage and aggregation of heat-damaged D1 protein in spinach thylakoids. Biochim Biophys Acta - Bioenerg 1767: 838-84

Kosar F, Akram NA, Ashraf M, Ahmad A, Alyemeni MN, Ahmad P (2020) Impact of exogenously applied trehalose on leaf biochemistry, achene yield and oil composition of sunflower under drought stress. Physiol Plant https://doi.org/10.1111/ppl.13155

Krause GH, Jahns P (2007) Non-photochemical Energy Dissipation Determined by Chlorophyll Fluorescence Quenching: Characterization and Function. In: Papageorgiou G.C., Govindjee (eds) Chlorophyll a Fluorescence. Advances in Photosynthesis and Respiration, vol 19. Springer, Dordrecht 463-495

Lamaoui M, Jemo M, Datla R, Bekkaoui F (2018) Heat and drought stresses in crops and approaches for their mitigation. Front Chem 6: 26

Lunn JE (2016) Sucrose Metabolism. In: eLS. John Wiley \& Sons, Ltd, Chichester, UK, pp 1-9

Marques da Silva J, Arrabaça MC (2004) Contributions of soluble carbohydrates to the osmotic adjustment in the $\mathrm{C} 4$ grass Setaria sphacelata: A comparison between rapidly and slowly imposed water stress. J Plant Physiol 161: 551-555

Minagawa J (2011) State transitions-the molecular remodeling of photosynthetic supercomplexes that controls energy flow in the chloroplast. Biochim Biophys Acta - Bioenerg. 1807: 897-905

Mittler R, Vanderauwera S, Gollery M, Van Breusegem F (2004) Reactive oxygen gene network of plants. Trends Plant Sci 9: 490-498

Moore G (2015) Strategic pre-breeding for wheat improvement. Nat Plants 1: 15018

Mueller-Cajar O (2017) The diverse AAA+ machines that repair inhibited Rubisco active sites. Front Mol Biosci 4

Murata N, Takahashi S, Nishiyama Y, Allakhverdiev SI (2007) Photoinhibition of photosystem II under 
environmental stress. Biochim Biophys Acta - Bioenerg. 1767: 414-421

Nägele T, Henkel S, Hörmiller I, et al (2010) Mathematical modeling of the central carbohydrate metabolism in arabidopsis reveals a substantial regulatory influence of vacuolar invertase on whole plant carbon metabolism. Plant Physiol 153: 260-272

Oxborough K, Baker NR (1997) Resolving chlorophyll a fluorescence images of photosynthetic efficiency into photochemical and non-photochemical components - Calculation of qP and Fv'/Fm' without measuring Fo'. Photosynth Res 54: 135-142

Parry MAJ, Andralojc PJ, Parmar S, Keys AJ, Habash D, Paul, MJ, Alred R, Quick WP, Servaites JC (1997) Regulation of Rubisco by inhibitors in the light. Plant, Cell Environ 20: 528-534

Pelleschi S, Rocher JP, Prioul JL (1997) Effect of water restriction on carbohydrate metabolism and photosynthesis in mature maize leaves. Plant, Cell Environ 20: 493-503

Perdomo JA, Capó-Bauçà S, Carmo-Silva E, Galmés J (2017) Rubisco and Rubisco Activase Play an Important Role in the Biochemical Limitations of Photosynthesis in Rice, Wheat, and Maize under High Temperature and Water Deficit. Front Plant Sci 8: 490

Perdomo JA, Carmo-Silva E, Hermida-Carrera C, Flexas J, Galmés J (2016) Acclimation of Biochemical and Diffusive Components of Photosynthesis in Rice, Wheat, and Maize to Heat and Water Deficit: Implications for Modeling Photosynthesis. Front Plant Sci 7: 1-16

Pinheiro C, Chaves MM (2011) Photosynthesis and drought: Can we make metabolic connections from available data? J Exp Bot 62: 869-882

Raja V, Qadir SU, Alyemeni MN, Ahmad P (2020) Impact of drought and heat stress individually and in combination on physio-biochemical parameters, antioxidant responses, and gene expression in Solanum lycopersicum. 3 Biotech 10:208

Rohart F, Gautier B, Singh A, Lê Cao K-A (2017) mixOmics: An R package for 'omics feature selection and multiple data integration. PLOS Comput Biol 13: e1005752

Roitsch T (1999) Source-sink regulation by sugar and stress. Curr Opin Plant Biol 2: 198-206

Roitsch T, González MC (2004) Function and regulation of plant invertases: Sweet sensations. Trends Plant Sci 9: 606-613

Ruan Y-L (2014) Sucrose Metabolism: Gateway to Diverse Carbon Use and Sugar Signaling. Annu Rev Plant Biol 65: 33-67

Ruan YL, Jin Y, Yang YJ, Li GJ, Boyer JS (2010) Sugar input, metabolism, and signaling mediated by invertase: Roles in development, yield potential, and response to drought and heat. Mol Plant 3: 942-955

Ruban AV (2016) Nonphotochemical chlorophyll fluorescence quenching: Mechanism and effectiveness in protecting plants from photodamage. Plant Physiol 170: 1903-16

Ruban A V., Johnson MP, Duffy CDP (2012) The photoprotective molecular switch in the photosystem II antenna. Biochim Biophys Acta - Bioenerg 1817: 167-181

Rumeau D, Peltier G, Cournac L (2007) Chlororespiration and cyclic electron flow around PSI during 
photosynthesis and plant stress response. Plant, Cell Environ 30: 1041-1051

Salvucci ME, Crafts-Brandner SJ (2004a) Inhibition of photosynthesis by heat stress: the activation state of Rubisco as a limiting factor in photosynthesis. Physiol Plant 120: 179-186

Salvucci ME, Crafts-Brandner SJ (2004b) Mechanism for deactivation of Rubisco under moderate heat stress. Physiol Plant 122: 513-519

Salvucci ME, Crafts-Brandner SJ (2004c) Inhibition of photosynthesis by heat stress: The activation state of Rubisco as a limiting factor in photosynthesis. Physiol Plant 120: 179-186

Scafaro AP, Bautsoens N, den Boer B, Van Rie J, Gallé A (2019) A Conserved Sequence from HeatAdapted Species Improves Rubisco Activase Thermostability in Wheat. Plant Physiol 181: 43-54

Scafaro AP, Gallé A, Van Rie J, Carmo-Silva E, Salvucci ME, Atwell BJ (2016) Heat tolerance in a wild Oryza species is attributed to maintenance of Rubisco activation by a thermally stable Rubisco activase ortholog. New Phytol 211: 899-911

Secchi F, Zwieniecki MA (2016) Accumulation of sugars in the xylem apoplast observed under water stress conditions is controlled by xylem pH. Plant Cell Environ 39: 2350-2360

Secchi F, Zwieniecki MA (2011) Sensing embolism in xylem vessels: The role of sucrose as a trigger for refilling. Plant, Cell Environ 34: 514-524

Shivhare D, Mueller-Cajar O (2017) In vitro characterization of thermostable CAM rubisco activase reveals a rubisco interacting surface loop. Plant Physiol 174: 1505-1516

Šiffel P, Braunová Z (1999) Release and aggregation of the light-harvesting complex in intact leaves subjected to strong $\mathrm{CO}^{2}$ deficit. Photosynth Res 61: 217-226

Šiffel P, Vácha F (1998) Aggregation of the Light-Harvesting Complex in Intact Leaves of Tobacco plants stressed by $\mathrm{CO}^{2}$ deficit. Photochem Photobiol 67: 304-311

Solís Moya E, Camacho Casas MA (2016) Evaluation of the Stress Adaptive Trait Yield Nursery (SATYN) in irrigated wheat growing locations in Mexico during the 2015-16 growing season. Proc 2nd Int TRIGO Yield Potential 10-14

Stirbet A, Govindjee (2011) On the relation between the Kautsky effect (chlorophyll a fluorescence induction) and Photosystem II: Basics and applications of the OJIP fluorescence transient. J Photochem Photobiol B Biol 104: 236-257

Strasser RJ, Tsimilli-Michael M, Srivastava A (2004) Analysis of the Chlorophyll a Fluorescence Transient. In: Papageorgiou GC, Govindjee (eds) Chlorophyll a Fluorescence. Advances in Photosynthesis and Respiration, vol 19. Springer, Dordrecht

Takahashi S, Murata N (2008) How do environmental stresses accelerate photoinhibition? Trends Plant Sci 13: $178-182$

Tang Y, Wen X, Lu Q, Yang Z, Cheng Z, Lu C (2007) Heat stress induces an aggregation of the lightharvesting complex of photosystem II in spinach plants. Plant Physiol 143: 629-38.

Tiwari A, Jajoo A, Bharti S (2008) Heat-induced changes in the EPR signal of tyrosine D (Y(D)OX) a possible role of Cytochrome b559. J Bioenerg Biomembr 40: 237-243 
Tricker PJ, Elhabti A, Schmidt J, Fleury D (2018) The physiological and genetic basis of combined drought and heat tolerance in wheat. J Exp Bot 69: 3195-3210

Trouverie J, Thévenot C, Rocher JP, Sotta B, Prioul JL (2003) The role of abscisic acid in the response of a specific vacuolar invertase to water stress in the adult maize leaf. J Exp Bot 54: 2177-2186

Tsimilli-Michael M, Strasser RJ (2008) In vivo assessment of stress impact on plant's vitality: Applications in detecting and evaluating the beneficial role of mycorrhization on host plants. In: Mycorrhiza: State of the Art, Genetics and Molecular Biology, Eco-Function, Biotechnology, Eco-Physiology, Structure and Systematics, $3^{\text {rd }}$ edn. Springer-Verlag Berlin Heidelberg, pp 679703

von Caemmerer S, Farquhar GD (1981) Some relationships between the biochemistry of photosynthesis and the gas exchange of leaves. Planta 153: 376-387

Walker BJ, VanLoocke A, Bernacchi CJ, Ort DR (2016) The Costs of Photorespiration to Food Production Now and in the Future. Annu Rev Plant Biol 67: 107-129

Wang D, Fu A (2016) The Plastid Terminal Oxidase is a Key Factor Balancing the Redox State of Thylakoid Membrane. In: Enzymes. Academic Press, pp 143-171

Wang L, Zheng Y, Ding S, Zhang Q, Chen Y, Zhang J (2017) Molecular cloning, structure, phylogeny and expression analysis of the invertase gene family in sugarcane. BMC Plant Biol 17: 109

Weiszmann J, Fürtauer L, Weckwerth W, Nägele T (2018) Vacuolar sucrose cleavage prevents limitation of cytosolic carbohydrate metabolism and stabilizes photosynthesis under abiotic stress. FEBS J 285: 4082-4098

Yamamoto Y (2016) Quality Control of Photosystem II: The Mechanisms for Avoidance and Tolerance of Light and Heat Stresses are Closely Linked to Membrane Fluidity of the Thylakoids. Front Plant Sci 7: 1136

Zampieri M, Ceglar A, Dentener F, Toreti A (2017) Wheat yield loss attributable to heat waves, drought and water excess at the global, national and subnational scales. Environ Res Lett 12

Zandalinas SI, Mittler R, Balfagón D, ArbonaV, Gómez-Cadenas A (2018) Plant adaptations to the combination of drought and high temperatures. Physiol Plant 162: 2-12

Zhao C, Liu B, Piao S, et al (2017) Temperature increase reduces global yields of major crops in four independent estimates. Proc Natl Acad Sci USA 114: 9326-9331

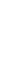

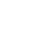

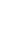

(1) 
707

Table 1. Leaf and soil water status, and canopy temperature of Paragon and Sokoll wheat plants exposed to a combination of heat stress and water deficit and recovery from heat stress conditions. Plants were grown for 3 weeks, then exposed to heat stress $\left(38^{\circ} \mathrm{C}\right.$ versus control, $\left.25^{\circ} \mathrm{C}\right)$, water deficit (WD versus well-watered $\mathrm{WW})$ and re-watered at control temperature $\left(25^{\circ} \mathrm{C}\right)$ after heat stress conditions $\left(\mathrm{RWW} 38^{\circ} \mathrm{C}\right.$ and $\left.\mathrm{RWD} 38^{\circ} \mathrm{C}\right)$. Values are means $\pm \mathrm{SD}(\mathrm{n}=5$ biological replicates). Different letters denote statistically significant differences between treatments (Duncan analysis, $P<0.05$ ). LRWC- leaf relative water content; LWP- leaf water potential; SRWC- soil relative water content; Tcanopy- canopy temperature.

\begin{tabular}{|c|c|c|c|c|c|c|}
\hline \multicolumn{2}{|c|}{ Treatment } & Genotype & LRWC $\left(\% \mathbf{H}_{2} \mathrm{O}\right)$ & LWP (MPa) & $\mathrm{SRWC}\left(\% \mathrm{H}_{2} \mathrm{O}\right)$ & Tcanopy $\left({ }^{\circ} \mathbf{C}\right)$ \\
\hline \multirow{4}{*}{$25^{\circ} \mathrm{C}$} & \multirow{2}{*}{ WW } & Paragon & $90.11 \pm 8.82 \mathrm{c}$ & $-0.50 \pm 0.08 c$ & $88.45 \pm 5.84 \mathrm{c}$ & $26.87 \pm 0.65 a$ \\
\hline & & Sokoll & $90.20 \pm 1.73 \mathrm{c}$ & $-0.81 \pm 0.12 b c$ & $80.11 \pm 4.88 \mathrm{~b}$ & $26.33 \pm 0.19 a$ \\
\hline & \multirow{2}{*}{ WD } & Paragon & $68.24 \pm 12.45 b$ & $-1.16 \pm 0.16 a b$ & $26.74 \pm 4.84 \mathrm{a}$ & $28.79 \pm 0.62 b$ \\
\hline & & Sokoll & $31.89 \pm 8.87 \mathrm{a}$ & $-1.39 \pm 0.10 \mathrm{a}$ & $29.12 \pm 0.92 \mathrm{a}$ & $27.89 \pm 1.10 \mathrm{~b}$ \\
\hline \multirow{4}{*}{$38^{\circ} \mathrm{C}$} & \multirow{2}{*}{ WW } & Paragon & $78.60 \pm 8.47 \mathrm{bc}$ & $-0.82 \pm 0.06 b c$ & $87.57 \pm 2.11 \mathrm{c}$ & $35.04 \pm 0.98 \mathrm{c}$ \\
\hline & & Sokoll & $80.38 \pm 4.74 b c$ & $-0.77 \pm 0.09 b c$ & $75.02 \pm 5.32 b$ & $33.37 \pm 0.40 \mathrm{~d}$ \\
\hline & \multirow{2}{*}{ WD } & Paragon & $39.60 \pm 17.71 \mathrm{a}$ & $-1.30 \pm 0.59 a$ & $30.44 \pm 1.69 \mathrm{a}$ & $36.95 \pm 0.74 \mathrm{e}$ \\
\hline & & Sokoll & $43.06 \pm 26.64 \mathrm{a}$ & $-1.55 \pm 0.58 \mathrm{a}$ & $28.42 \pm 2.72 \mathrm{a}$ & $37.52 \pm 0.47 \mathrm{e}$ \\
\hline \multirow{4}{*}{$\begin{array}{l}\overrightarrow{0} \\
\stackrel{0}{0} \\
\stackrel{0}{0}\end{array}$} & \multirow{2}{*}{$\begin{array}{l}\text { RWW } \\
38^{\circ} \mathrm{C}\end{array}$} & Paragon & $86.46 \pm 1.36 \mathrm{c}$ & $-0.76 \pm 0.03 b c$ & $90.13 \pm 5.25 \mathrm{c}$ & $25.71 \pm 0.3 \mathrm{a}$ \\
\hline & & Sokoll & $94.91 \pm 4.82 \mathrm{~cd}$ & $-0.74 \pm 0.05 b c$ & $91.69 \pm 6.14 \mathrm{c}$ & $25.58 \pm 0.4 \mathrm{a}$ \\
\hline & \multirow{2}{*}{$\begin{array}{l}\text { RWD } \\
38{ }^{\circ} \mathrm{C}\end{array}$} & Paragon & $90.83 \pm 3.42 \mathrm{c}$ & $-0.72 \pm 0.1 b c$ & $88.96 \pm 4.1 \mathrm{c}$ & $26.33 \pm 0.44 \mathrm{a}$ \\
\hline & & Sokoll & $78.31 \pm 21.18 \mathrm{bc}$ & $-0.98 \pm 0.16 \mathrm{ab}$ & $89.3 \pm 3.22 \mathrm{c}$ & $26.43 \pm 0.21 \mathrm{a}$ \\
\hline
\end{tabular}

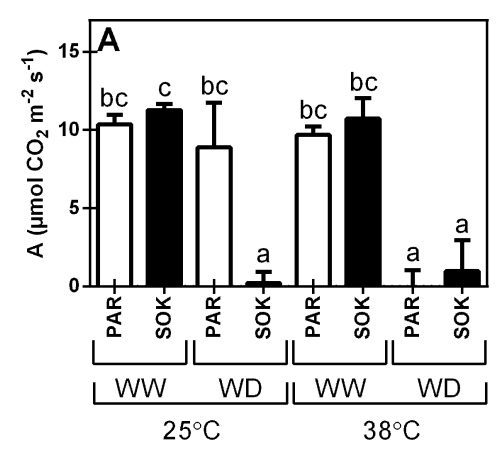

Figure 1. Steady-state photosynthesis of Paragon (PAR) and Sokoll (SOK) wheat plants exposed to a combination of heat stress and water deficit. (A) Net $\mathrm{CO}_{2}$ assimilation, (B) stomatal conductance (gs) and (C) electron transport rate (ETR) were measured at growth light and ambient $\mathrm{CO}_{2}$ in fully expanded leaves of wheat 3-week-old plants under well-watered (WW) and water deficit (WD) conditions and exposed to control $\left(25^{\circ} \mathrm{C}\right)$ and heat stress conditions $\left(38^{\circ} \mathrm{C}\right)$. Values are means $\pm \operatorname{SD}(n=5$ biological replicates). Different letters denote statistically significant differences between treatments (Duncan analysis, $P<0.05)$. 


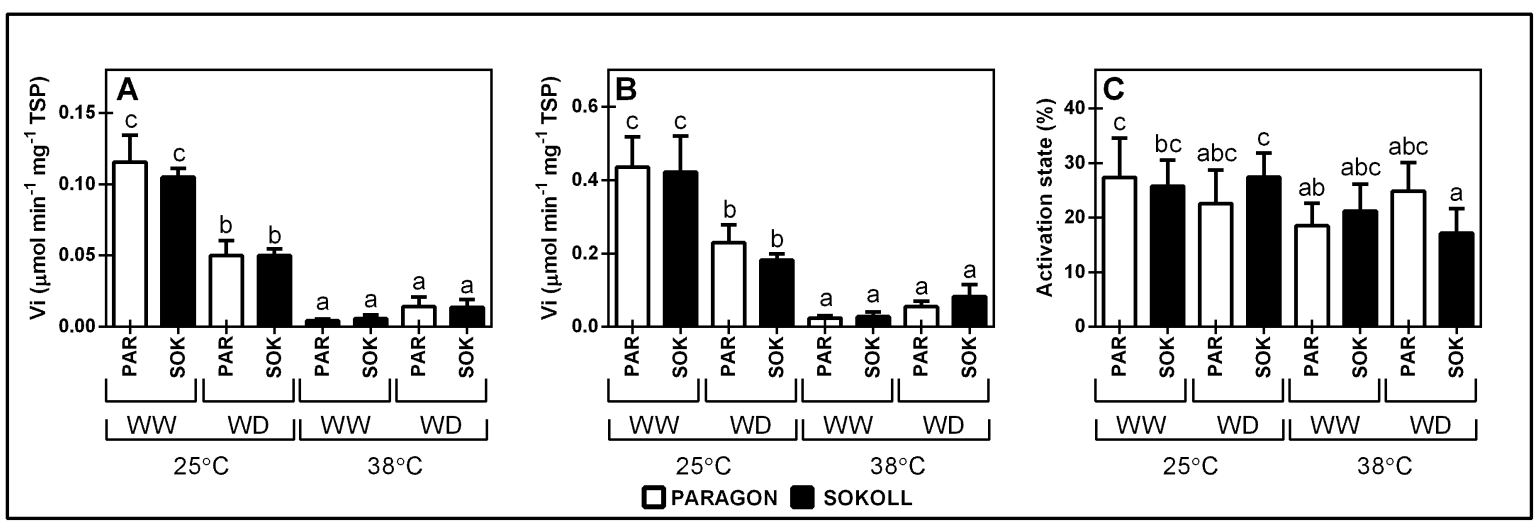

Measured at $38^{\circ} \mathrm{C}$
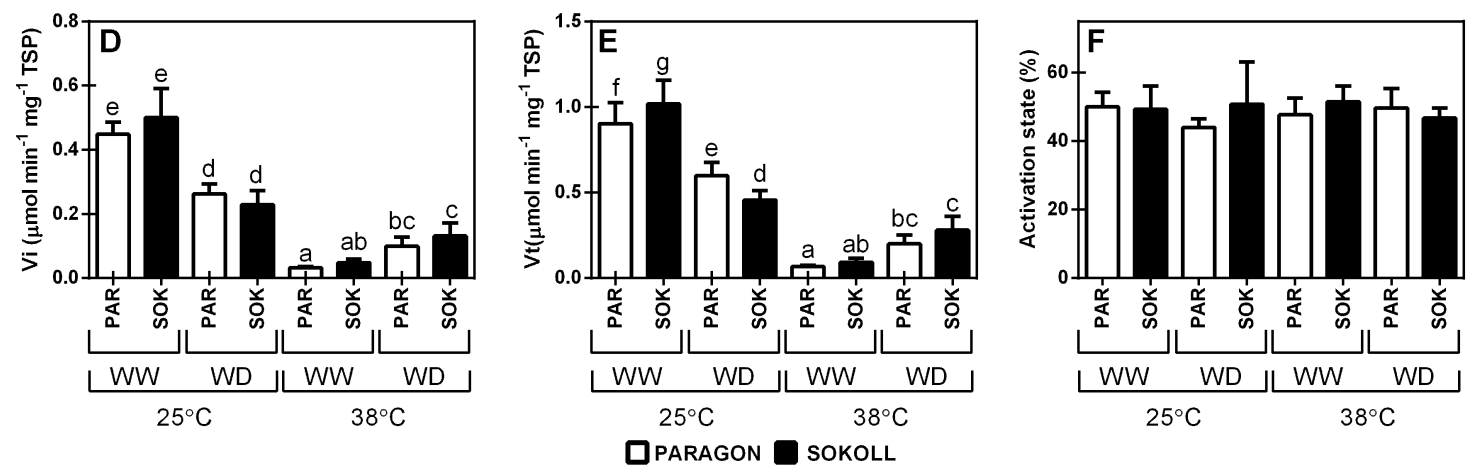

Figure 2. Effect of high temperature and drought on Rubisco activity (expressed by total soluble protein, TSP) and activation state in two wheat genotypes, Paragon (PAR) and Sokoll (SOK). (A-C) Rubisco initial (Vi) and total (Vt) activities and activation state were measured at $25^{\circ} \mathrm{C}$ and (D-F) $38^{\circ} \mathrm{C}$ in extracts of fully expanded leaves from 3-week-old wheat plants under well-watered (WW) and water deficit (WD) conditions and exposed to control $\left(25^{\circ} \mathrm{C}\right)$ and heat stress conditions $\left(38^{\circ} \mathrm{C}\right)$. Values are means \pm SD ( $n=4-5$ biological replicates). Different letters denote statistically significant differences between treatments (Duncan analysis, $P<0.05$ ). 

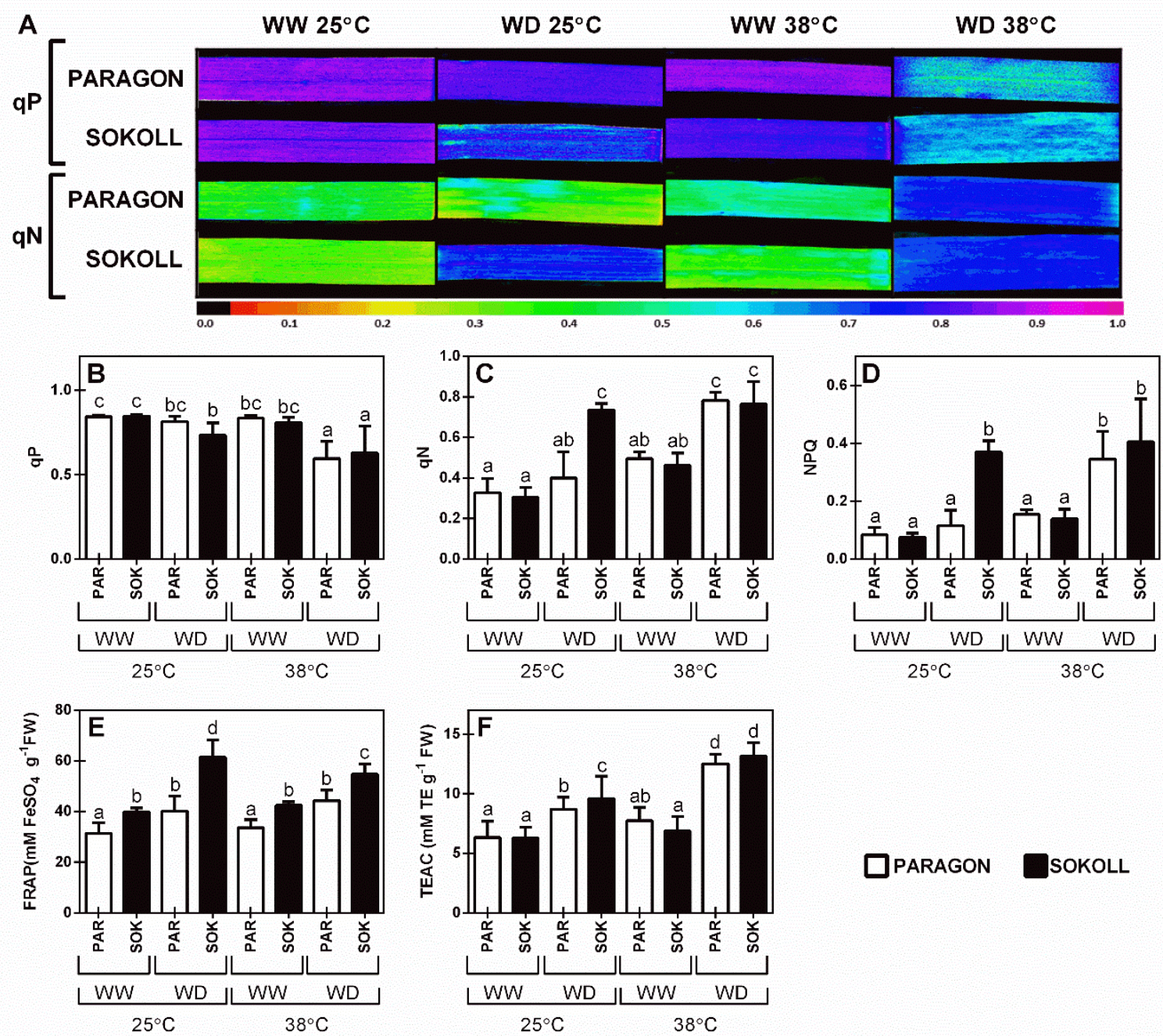

DPARAGONOLL

Figure 3. Effect of high temperature and drought on chlorophyll $a$ fluorescence and the antioxidant scavenging capacity in two wheat genotypes, Paragon (PAR) and Sokoll (SOK). (A) Chlorophyll $a$ fluorescence imaging of the photochemical (qP) and non-photochemical (qN) quenching components in representative leaves. (B) Photochemical quenching (qP), (C) non-photochemical quenching (qN) (D) total non-photochemical quenching (NPQ), (E) ferric reducing antioxidant power (FRAP) and (F) trolox equivalents antioxidant capacity (TEAC) in fully expanded leaves of 3-week-old wheat plants under well-watered (WW) and water deficit (WD) conditions and exposed to control $\left(25^{\circ} \mathrm{C}\right)$ and heat stress conditions $\left(38^{\circ} \mathrm{C}\right)$. Values are means $\pm \operatorname{SD}(n=4-5$ biological replicates). Different letters denote statistically significant differences between treatments (Duncan analysis, $P<0.05$ ). 

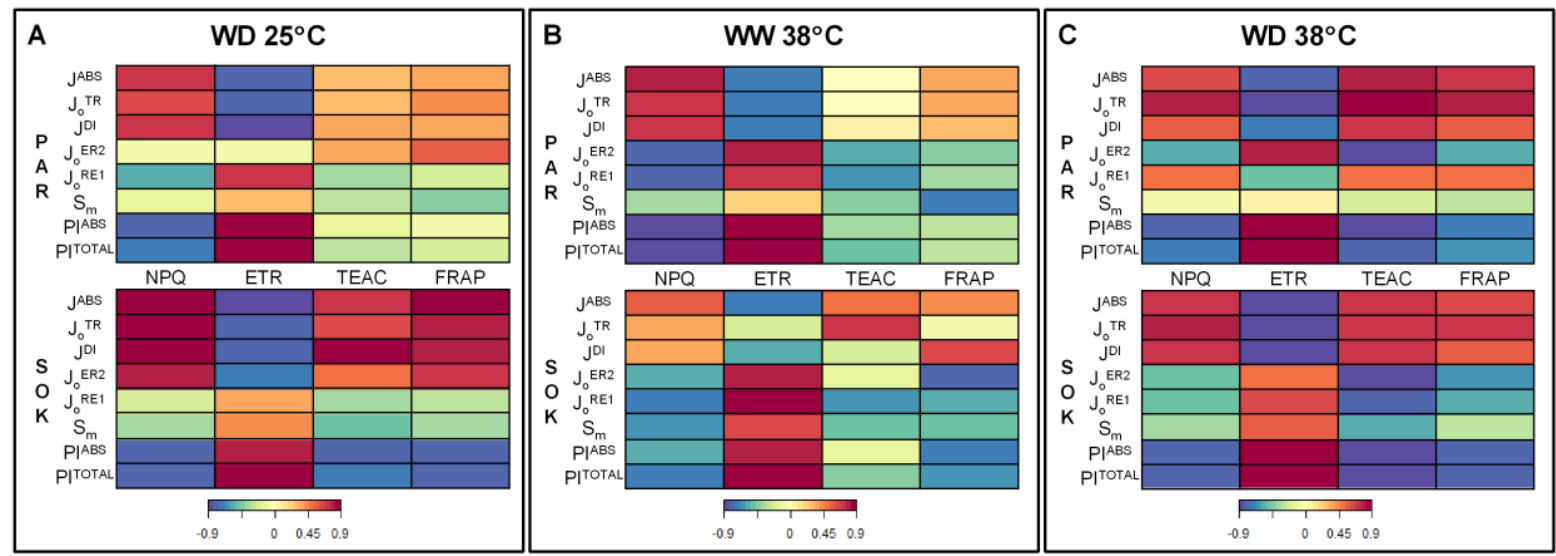

Figure 4. Heatmap representation of the correlation between chlorophyll $a$ fluorescence kinetics (OJIP

737 parameters) and antioxidant capacity or steady-state chlorophyll a fluorescence of two wheat genotypes,

738 Paragon (PAR) and Sokoll (SOK), under different stresses. Canonical correlations were determined according to the effect of (A) water deficit (at $25^{\circ} \mathrm{C}, \mathrm{WD} 25^{\circ} \mathrm{C}$ ), (B) high temperatures (well-watered, $\left.\mathrm{WW} 38^{\circ} \mathrm{C}\right)$, and $(\mathrm{C})$ water deficit combined with high temperatures $\left(\mathrm{WD} 38^{\circ} \mathrm{C}\right)$ relative to control plants $\left(\mathrm{WW} 25^{\circ} \mathrm{C}\right)$. All parameters were measured in fully expanded leaves of 3-week-old plants. OJIP parameters included are: absorbed photon flux $\left(\mathrm{J}^{\mathrm{ABS}}\right)$; maximum trapped exciton flux $\left(\mathrm{J}_{\mathrm{o}}{ }^{\mathrm{TR}}\right)$; dissipated energy flux $\left(\mathrm{J}^{\mathrm{DI}}\right)$; electron transport flux from $\mathrm{Q}_{\mathrm{A}}$ to $\mathrm{Q}_{\mathrm{B}}\left(\mathrm{J}_{\mathrm{o}}{ }^{\mathrm{ET2}}\right)$; electron transport flux until PSI acceptors $\left(\mathrm{J}_{\mathrm{o}}{ }^{\mathrm{RE1}}\right)$; number of electron carriers per electron transport chain $\left(\mathrm{S}_{\mathrm{m}}\right)$; performance index for energy conservation from photons absorbed by PSII antenna to the reduction of $\mathrm{QB}\left(\mathrm{PI}^{\mathrm{ABS}}\right)$ and until the reduction of PSI acceptors $\left(\mathrm{PI}^{\mathrm{TOTAL}}\right)$. Mean values $\pm \mathrm{SD}(\mathrm{n}=5$ biological replicates $)$ are in supplementary data, Table S1. Steady-state chlorophyll $a$ fluorescence parameters are nonphotochemical quenching (NPQ) and electron transport rate (ETR). Antioxidant capacity was determined by trolox equivalents antioxidant capacity (TEAC) and ferric reducing antioxidant power (FRAP). Different colours denote positive (red) or negative (blue) correlations between variables ( $\mathrm{n}=5$ biological replicates). 

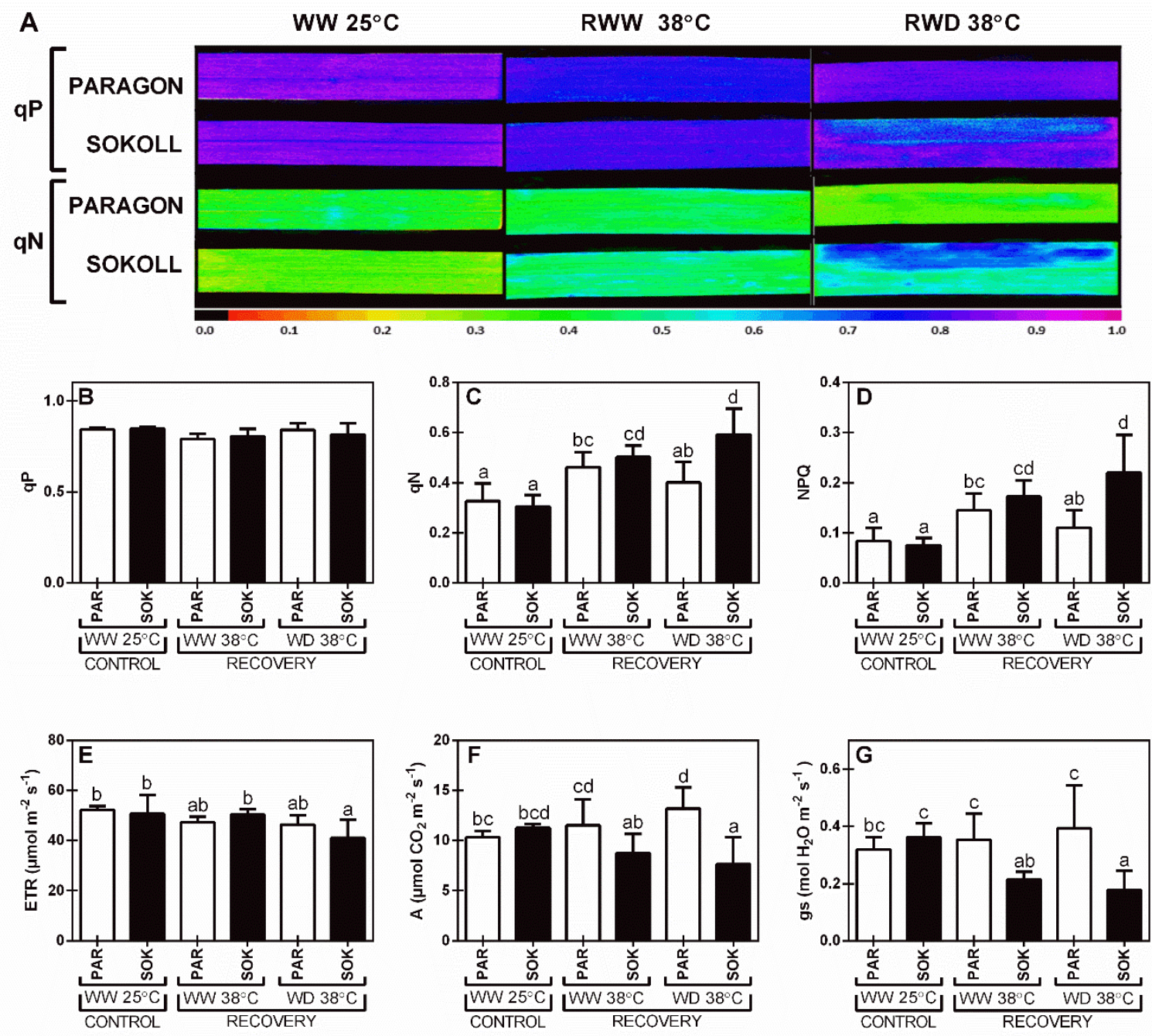

DPARAGON

SOKOLL

753 Figure 5. Recovery of the photochemistry and stomatal function of two wheat genotypes, Paragon

754 (PAR) and Sokoll (SOK), after exposure to high temperatures and water deficit. (A) Chlorophyll $a$

755 fluorescence imaging of the photochemical (qP) and non-photochemical (qN) quenching components

756 in representative leaves. (B) Photochemical quenching (qP), (C) non-photochemical quenching (qN),

757 (D) total non-photochemical quenching (NPQ), (E) electron transport rate (ETR), (F) net photosynthetic

758 assimilation rate (A), (G) stomatal conductance (gs). Measurements at growth PPFD in fully expanded

759 leaves of 33-day-old wheat plants recovering for 7 days under well-watered (WW) conditions and $25^{\circ} \mathrm{C}$

760 after exposure to WW (RWW $38^{\circ} \mathrm{C}$ ) or water deficit $\left(\mathrm{RWD} 38^{\circ} \mathrm{C}\right)$ conditions and high temperature

$761\left(38^{\circ} \mathrm{C}\right)$ for 5 days. Values are means $\pm \mathrm{SD}(\mathrm{n}=5$ biological replicates). Different letters denote statistically significant differences between treatments (Duncan analysis, $P<0.05$ ). 


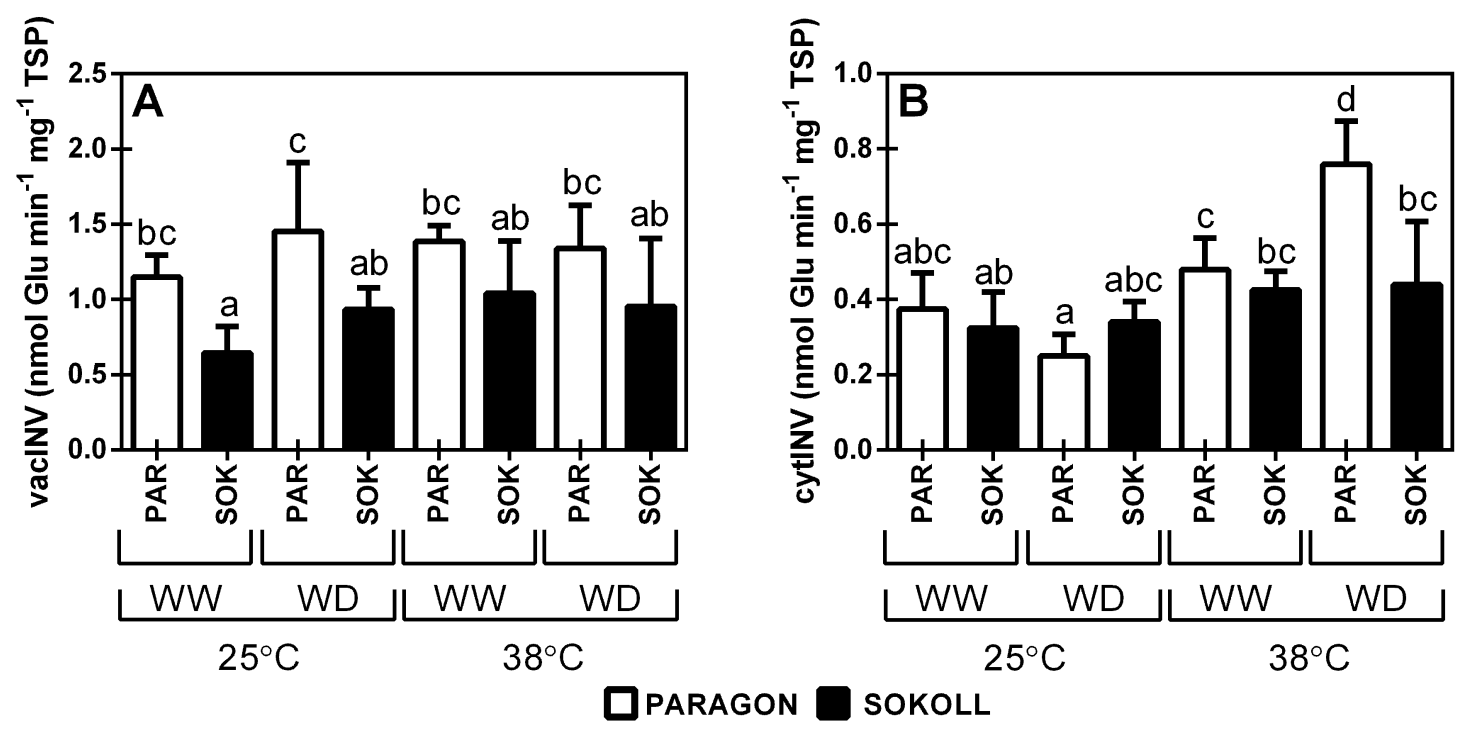

763

764

765

766

767

768

769

770

771

772

773

774

775

776

777

778

779

780

781

782

783

Figure 6. Effect of high temperature and water deficit on cytoplasmic and vacuolar invertases activities in two wheat genotypes, Paragon (PAR) and Sokoll (SOK). (A) Vacuolar Invertase (vacINV) and (B) cytoplasmic invertase (cytINV) activities were measured at $30^{\circ} \mathrm{C}$ in fully expanded leaves of 3-weekold wheat plants under well-watered (WW) and water deficit (WD) conditions and exposed to control $\left(25^{\circ} \mathrm{C}\right)$ and high temperatures $\left(38^{\circ} \mathrm{C}\right)$. Values are means $\pm \mathrm{SD}(\mathrm{n}=4-5$ biological replicates). Different letters denote statistically significant differences between treatments (Duncan analysis, $P<0.05$ ).

\section{Supplementary data}

Fig.S1. Effect of high temperature and drought on Rubisco activity (expressed by leaf area) and activation state in two wheat genotypes, Paragon (PAR) and Sokoll (SOK).

Table S1. Pearson correlation matrix between net photosynthetic assimilation rate (A), stomatal conductance (gs), electron transport rate (ETR) and cytoplasmic invertase (cytINV) in two wheat genotypes, Paragon and Sokoll, under well-watered (WW) and water deficit (WD) conditions and exposed to control $\left(25^{\circ} \mathrm{C}\right)$ and high temperatures $\left(38^{\circ} \mathrm{C}\right)$.

Table S2. OJIP parameters of Paragon and Sokoll wheat plants exposed to a combination of heat stress and water deficit and recovered under well-watered conditions.

Fig.S2. Chlorophyll $a$ fluorescence induction curves (OJIP curves) of Paragon and Sokoll wheat plants exposed to water deficit, heat stress, a combination of heat stress and water deficit and recovered under well-watered conditions. 